\title{
Uptake and effects of a mixture of widely used therapeutic drugs in Eruca sativa L. and Zea mays L. plants
}

\author{
Milena Marsoni ${ }^{\mathrm{a}}$, Fabrizio De Mattia ${ }^{\mathrm{b}}$, Massimo Labra ${ }^{\mathrm{c}}$, Antonella Bruno ${ }^{\mathrm{c}}$, \\ Marcella Bracale ${ }^{a}$, Candida Vannini ${ }^{\mathrm{a}, *}$ \\ a Department of Biotechnology and Life Science, University of Insubria, Via J. H. Dunant 3, I-21100 Varese, Italy \\ ${ }^{\mathrm{b}}$ FEM2 Ambiente Srl, Spin Off Company of University of Milano-Bicocca, Piazza della Scienza 2, I-20126 Milan, Italy \\ ${ }^{\mathrm{c}}$ Department of Biotechnology and Biosciences, University of Milano-Bicocca, Piazza della Scienza 2, I-20126 Milan, Italy
}

\section{A R T I C L E I N F O}

Article history:

Received 13 February 2014

Received in revised form

28 May 2014

Accepted 28 May 2014

Keywords:

Pharmaceutical pollution

Eruca sativa

Zea mays

Human health

\begin{abstract}
A B S T R A C T
Pharmaceutically active compounds (PACs) are continuously dispersed into the environment due to human and veterinary use, giving rise to their potential accumulation in edible plants. In this study, Eruca sativa L. and Zea mays L. were selected to determine the potential uptake and accumulation of eight different PACs (Salbutamol, Atenolol, Lincomycin, Cyclophosphamide, Carbamazepine, Bezafibrate, Ofloxacin and Ranitidine) designed for human use. To mimic environmental conditions, the plants were grown in pots and irrigated with water spiked with a mixture of PACs at concentrations found in Italian wastewaters and rivers. Moreover, $10 \times$ and $100 \times$ concentrations of these pharmaceuticals were also tested. The presence of the pharmaceuticals was tested in the edible parts of the plants, namely leaves for E. sativa and grains for Z. mays. Quantification was performed by liquid chromatography mass spectroscopy (LC/MS/MS). In the grains of $100 \times$ treated Z. mays, only atenolol, lincomycin and carbamazepine were above the limit of detection (LOD). At the same concentration in E. sativa plants the uptake of all PACs was > LOD. Lincomycin and oflaxacin were above the limit of quantitation in all conditions tested in E. sativa. The results suggest that uptake of some pharmaceuticals from the soil may indeed be a potential transport route to plants and that these environmental pollutants can reach different edible parts of the selected crops. Measurements of the concentrations of these pharmaceuticals in plant materials were used to model potential adult human exposure to these compounds. The results indicate that under the current experimental conditions, crops exposed to the selected pharmaceutical mixture would not have any negative effects on human health. Moreover, no significant differences in the growth of E. sativa or Z. mays plants irrigated with PAC-spiked vs. non-spiked water were observed.
\end{abstract}

(c) 2014 Elsevier Inc. All rights reserved.

\section{Introduction}

Pharmaceutically active compounds (PACs) may enter the environment through patient excretions, discharge from pharmaceutical manufacturing facilities, and improper disposal (Sharma et al., 2013). Pharmaceuticals are not completely metabolized in the body and may therefore be excreted in an active form able to elicit a biological response at very low concentrations (Rang et al., 1999; Boxall et al., 2002; Sarmah et al., 2006). The presence of pharmaceutical residues has been documented in ground, surface, and even drinking water (Arnold et al., 2013; Boxall et al., 2012; De Lorenzo and Fleming, 2012), and modern water treatment systems are not completely able to effectively remove all PACs (Rivera-Utrilla et al.,

\footnotetext{
* Corresponding author. Fax: +39332421390.

E-mail address: candida.vannini@uninsubria.it (C. Vannini).
}

2013). Throughout Europe, wastewater and rivers contain a broad variety of pharmaceutical substances and their metabolites (http:// www.eea.europa.eu). PAC concentrations in the environment may range between $\mathrm{ng}^{-1}$ and $\mu \mathrm{g} \mathrm{l}^{-1}$. While it is accepted that these concentrations are too low to present a short-term risk for humans, the long-term toxicity of PACs in the environment remains to be characterized. Indeed, pharmaceutical substances are specifically designed to be chemically stable and resistant to degradation and to have a biological effect on living organisms. The toxic effects of PACs on aquatic organisms have been well-documented (Carlsson et al., 2009; Kümmerer, 2008; Corcoran et al., 2010; Vannini et al., 2011). in vitro tests performed on human cells using a mixture of PACs suggest that these PACs inhibit cell proliferation and affect cell physiology and morphology (Pomati et al., 2006). These effects are strictly related to pollutant concentrations and combinations, exposure times, and other environmental factors. For these reasons, to assess the real risk of pharmaceutical contaminants in water on 
human health, the access of the body to these pollutants should be investigated (Kumar and Xagoraraki, 2010). Agriculture represents an important gateway of pharmaceutical contaminants into the food chain due to the high demand for water from different freshwater sources and the use of sewage sludge compost (Munoz et al., 2010; Piel et al., 2012). Several studies have explored the uptake in crops of PACs designed for both human medical and veterinary use. Results demonstrated that this uptake is apparently specific to both plant species and chemicals. (Wu et al., 2010, 2012; Tanoue et al., 2012; Dolliver et al., 2007; Eggen et al., 2011; Herklotz et al., 2010; Dodgen et al., 2013; Calderon-Preciado et al., 2013). However, although some existing studies have considered realistic PACs concentrations such as Shenker et al. (2011), most of the previous reports have used very relevant concentrations $\left(\mu \mathrm{gl}^{-1}\right)$ of chemicals (compared to those present in the environment). Moreover, single drugs or mixtures of a few compounds were employed for the toxicological tests performed in these studies.

The objective of the present study was to evaluate the ability of edible plants to uptake a mixture of eight PACs. The selected chemicals are a subset of PACs found in Italian rivers by Pomati et al. (2006) and the lowest concentration used is based on environmental levels. Moreover, the selected PACs are representative of a wide range of physicochemical properties (Table 1) and environmental persistence.

Two different crops were selected. The first crop, Eruca sativa L. (arugula, rocket) is a fast-growing plant that requires consistent water irrigation and is cultivated both at the industrial level and in the home garden. The edible portion of this vegetable is the leaves, which can be harvested after 20 days of growth and sequentially harvested after re-growth; therefore, our toxicological analysis was performed on the leaves of this crop. The second plant was Zea mays L. (maize, corn), one of the most economically important food crops in the world, which demands substantial water volume during plant growth and flowering. In this crop, the edible portion is the kernels; thus, we estimated the uptake of PACs in corn kernels following plant irrigation with PACcontaminated water.

We also evaluated the phytotoxicity of the same PAC mixture by performing seed germination tests on filter paper and examining plant growth in the soil. PACs may elicit a biological response on non-target organisms because their molecular targets may be evolutionarily well-conserved. Green algae were predicted to have orthologs of 35 percent of the 1318 human drug targets tested (Gunnarsson et al., 2008), and homologous targets for PACs have been identified in plants (Brain et al., 2009; Rand-Weaver et al., 2013).
The importance of our study is to test the mixture of PACs rather than the individual chemical separately because this is the form in which the chemical are found in nature. Moreover, to study the uptake of PACs in edible portions of the crops is important to evaluate the potential risks to consume plant parts. Our results are important to use of reclaimed wastewater for irrigation and potentially for the use of sewage sludge amendment.

\section{Materials and methods}

\subsection{Chemicals and materials}

Salbutamol (SAL), Atenolol (ATN), Lincomycin (LIN), Cyclophosphamide (CPA), Carbamazepine (CBZ), Bezafibrate (BZF) was purchased from Sigma-Aldrich (Steinheim, Germany), Ofloxacin (OFX) and Ranitidine (RNT) was obtained from ICN Biochemicals (Meckenheim, Germany) and GlaxoSmithKline (Philadelphia, PA), respectively. Deuterated internal standard (IS) Salbutamol-D 3 (99.1 percent D) were purchased from CDN isotopes (Quebec, Canada). Stock solutions for all compounds were prepared in methanol $\left(1 \mathrm{mg} \mathrm{ml}^{-1}\right)$ and stored at $-20^{\circ} \mathrm{C}$. Working mixtures of the eight PACs were prepared just before use. Serial dilutions in a volume of one liter were made to obtain the three final concentrations: $100 \times, 10 \times$ and $1 \times$, the last one corresponding to the detected environmental levels (Table 1, Pomati et al., 2006). All solvent used (Sigma-Aldrich, Steinheim, Germany) were LC-MS grade. Oasis MCX 3 cc Vac Cartridge, (60 mg sorbent per cartridge) for solid phase extraction (SPE) were purchased from Waters Corp., Milford, MA.

\subsection{Plant materials and seed germination test}

E. sativa L. (Fratelli Ingegnoli, Milan, Italy) and Z. mays cv. Tevere (Monsanto, St. Louis, MO, USA) seeds were sterilized with 2.5 percent sodium hypochlorite for $15 \mathrm{~min}$ and thoroughly washed with distilled water. Hydrated seeds were transferred in Petri dishes $(100 \mathrm{~mm}$ diameter) containing a Whatman filter in the presence of $5 \mathrm{ml}$ of distilled water $\mathrm{pH} 7.1$ (control) or PACs solution at different concentration: $100 \times, 10 \times$ and $1 \times$. For each concentration 10 dishes, each containing 10 seeds, were prepared and incubated in the dark at $25{ }^{\circ} \mathrm{C}$. After $72 \mathrm{~h}$, the germinated seeds were counted according to the APAT protocol (APAT, 2002). Seeds were considered germinated when root elongation was $>3 \mathrm{~mm}$; a minimum of 80 percent germinated seeds in the control dishes was required (OECD, 1984; USEPA, 1996). Tests were performed in triplicate.

\subsection{Plant treatment}

E. sativa plants were grown in a controlled greenhouse $\left(25^{\circ} \mathrm{C}\right.$, with a $16 \mathrm{~h} / 8 \mathrm{~h}$ photoperiod) in pots ( $15 \mathrm{~cm}$ diameter, $12 \mathrm{~cm}$ height). Four seeds were sown in each pot containing $300 \mathrm{~g}$ of peat-based horticultural mixture (50 percent of organic matter and $\mathrm{pH}$ 7.1) and covered by a plastic film during germination. The pots were irrigated for the first 15 days with fresh water and after this period were irrigated three times for week with $50 \mathrm{ml}$ of water containing $0,1 \times, 10 \times, 100 \times$ PAC solutions. The drainage was collected and put back into the pot. Five pots (replicates) were used for each treatment. The treatments were continued for six

Table 1

Pharmaceuticals analyzed. $1 \times$ concentration is referred to environmental level of drugs detected in northern Italian rivers (Pomati et al., 2006)

\begin{tabular}{|c|c|c|c|c|c|c|c|c|}
\hline Pharmaceuticals & & Therapeutic category & $1 \times$ conc. $\left(\mathrm{ng} \mathrm{l}^{-1}\right)$ & MW (Da) & $\mathbf{p K a}^{\mathrm{a}}$ & $\log P^{g}$ & $f_{n}^{h}(p H$ 7.1) & $\log D_{\text {ow }}{ }^{g}$ \\
\hline Salbutamol & $(\mathrm{SAL})$ & Bronchodilator & 4.6 & 239.3 & $10.1 ; 9.4$ & 0.34 & 0.005 & -1.58 \\
\hline Atenolol & (ATN) & Anti-Arrhythmia & 241 & 266.33 & $9.6^{\mathrm{b}}$ & 0.43 & 0.003 & -2.06 \\
\hline Ranitidine & (RNT) & Histamine H2 Antagonists & 39 & 314.14 & 8.08 & 0.99 & 0.094 & -0.03 \\
\hline Lincomycin & (LIN) & Anti-Bacterial & 249 & 406.54 & $12.9^{\mathrm{c}}$ & -0.32 & 0.12 & -1.24 \\
\hline Ofloxacin & (OFX) & Anti-Bacterial & 150 & 361.37 & $6.2 ; 5.4$ & 0.65 & 0.11 & -0.01 \\
\hline Cyclophosphamide & (CPA) & Antineoplastic & 10 & 260.02 & $6.0^{\mathrm{d}}$ & 0.1 & 1 & +0.1 \\
\hline Carbamazepine & (CBZ) & Anticonvulsants & 33 & 236.27 & $13.9^{\mathrm{e}}$ & 2.25 & 1 & +2.77 \\
\hline Bezafibrate & (BZF) & Antilipemic & 57 & 361.12 & $3.61^{\mathrm{f}}$ & 4.25 & 0.0003 & +0.91 \\
\hline
\end{tabular}

a Predicted data from http://www.drugbank.ca/ (unless otherwise specified).

${ }^{\mathrm{b}}$ Merck index (2001).

c Sarmah et al. (2006).

d Mahoney et al. (2003).

e Tanoue et al. (2012)

f www.rochecanada.com.

${ }^{g}$ Predicted values (unless otherwise specified) from database of Royal Society of Chemistry: http://www.chemspider.com.

h Wu et al. (2013). 
weeks. At the end of the experiment, the whole aboveground plants were cut, rinsed with deionized water, drained and the biomass weight recorded. The tissues collected were then frozen in liquid nitrogen, ground and lyophilized. Samples were kept at $-20{ }^{\circ} \mathrm{C}$ until extraction.

In the case of $Z$. mays, plants were grown in a controlled greenhouse at $25{ }^{\circ} \mathrm{C}$, an illumination of $100-120 \mu \mathrm{mol}$ photon $\mathrm{m}^{-2} \mathrm{~s}^{-1}$ and photoperiod of $12 \mathrm{~h}$ in the vessels of $34 \mathrm{~cm}$ diameter, $30 \mathrm{~cm}$ height and 131 of volume. After germination plants were irrigated for the first 10 days with fresh water and subsequently with $500 \mathrm{ml}$ of water containing $0,1 \times, 10 \times, 100 \times$ PAC solutions every day. The duration of plant treatment experiment was 4 months up to the stage of fructification.

Kernels were rinsed with deionized water, drained, and the biomass weight recorded. Kernels were then frozen in liquid nitrogen, grounded, lyophilized and kept at $-20^{\circ} \mathrm{C}$ until extraction.

\subsection{PAC extraction}

PACs were extracted from plants material by ultrasonic solvent extractions (USE) followed by a cleaning step SPE. The USE protocol was adapted from Ternes et al. (2005). Samples ( $1 \mathrm{~g}$ dry weight) were spiked with $10 \mathrm{ng}$ of IS Salbutamol-D3, and successively extracted with $10 \mathrm{ml}$ methanol (two times) and $10 \mathrm{ml}$ acetone. In each extraction step, the samples were sonicated for $10 \mathrm{~min}$ and then centrifuged at $6000 \mathrm{rpm}$ for $10 \mathrm{~min}$. The supernatants were collected, evaporated to a volume of about $1 \mathrm{ml}$ by using a rotary evaporator (Laborota 4000, Heidolph) and diluted with water to a final volume of $50 \mathrm{ml}$.

The SPE was performed by using an Oasis MCX 3 cc Vac Cartridgeas described in Castiglioni et al. (2005). Briefly, the $\mathrm{pH}$ of plant extract was adjusted to 2.0 with 37 percent $\mathrm{HCl}$. After conditioning of cartridges ( $6 \mathrm{ml}$ of methanol, $3 \mathrm{ml}$ of water and $3 \mathrm{ml}$ of acidified water), the samples were passed through the cartridges under vacuum at a flow rate of $20 \mathrm{ml} \mathrm{min}{ }^{-1}$. The columns were vacuum-dried and eluted with $5 \mathrm{ml}$ of methanol and $2.5 \mathrm{ml}$ of 2 percent ammonia solution in methanol. The eluates were pooled, dried under air and stored at $-20{ }^{\circ} \mathrm{C}$. Before analysis samples were dissolved in $500 \mu \mathrm{l}$ of water and aliquots of $20 \mu \mathrm{l}$ were injected for HPLC analysis with an auto sampler.

\subsection{Chromatography and mass spectrometry}

The HPLC analysis was performed in a Finningan Surveyor MS plus HPLC system (Thermo Electron Corporation, CA, USA). Chromatography separations were conducted onto a Luna C8 column $50 \mathrm{~mm} \times 2 \mathrm{~mm}$ i.d., $3 \mu \mathrm{m}$ particle size (Phenomenex, Torrance, CA, USA). The elution $200 \mu \mathrm{l} \mathrm{min}{ }^{-1}$ ) was completed at room temperature in $10 \mathrm{~min}$ with linear gradient from 98 percent $A$ (formic acid 0.1 percent in water) to 95 percent of eluent B (formic acid 0.1 percent in acetonitrile).

The mass spectrometry analysis was done using a Finningan LXQ linear ion trap equipped with an ESI ion source (Thermo Electron Corporation, CA, USA). All pharmaceuticals were analyzed in positive mode (spray voltage $4.5 \mathrm{kV}$, capillary temperature $270{ }^{\circ} \mathrm{C}$ ). For each substance the optimization of collision energy, the choice of fragmentation products and the tuning parameters were done in continuous flow mode, by using standard solutions at concentration of $10 \mathrm{ng} \mathrm{Il}^{-1}$.

\subsection{Quantification and validation of the method}

Quantitative analysis of PACs was performed as described by Castiglioni et al. (2005) measuring the fragmentation products of each drug and of its standard. The characteristic precursor ion / product ion transitions are listed in Table 2. To help identification we compared also the Retention Times (RT) of compounds with the RT of corresponding reference standards. For the quantitative analysis, in order to compensate for a possible matrix effect, the peak area of each target compound was normalized with the peak area of the IS. The same procedure was used to plot calibration curves from the standard solutions. Five-point calibration curves ( 1 to $50 \mathrm{ng} \mathrm{ml}^{-1}$ ) were generated for each pharmaceutical.

The concentrations of the target compounds in plant samples were corrected by recovery ratios, which were calculated by spiking the control sample with the PAC mixture containing $15 \mathrm{ng}$ of each pharmaceutical. Procedural blanks (methanol, acetone) spiked with IS were added to each set of sample to control contamination. Variability was investigated by running three replicate analyses of a single sample.

The instrumental detection limit (IDL) and instrumental quantification limit (IQL) were determined by spiking a SPE eluate of control sample with decreasing amounts of pharmaceutical mixture, down to $0.5 \mathrm{ng}$, and determining at what concentration the signal to noise ratios were equal to 3 and 10, respectively.

\subsection{Statistical analyses}

Data were checked for normal distribution (Kolmogorov and Smirnov method) and homogeneity of variance (Bartlett method). ANOVA test was performed to test the effects of treatment (Control, $1 \times, 10 \times$ and $100 \times$ ) on percentage of germinated seed and root elongation. A Tukey HSD test was applied to compare the effects of treatment at each experimental time. Tests of significance were made at a 95 percent confidence level. Analyses were processed using GraphPad InStat 3.1 (GraphPad Software, 2009, CA, USA).

\section{Results and discussion}

\subsection{PAC quantification and method validation}

The recoveries for all compounds were higher than 70 percent except for the ranitidine (RNT, 48 percent) and oflaxacine (OFX, 37 percent) (Table 2). The recovery data are quite similar to those reported for pharmaceuticals detected in sewage treatment plant effluents (Castiglioni et al., 2005) and in algae (Vannini et al., 2011). As discussed by Castiglioni et al. (2005), the low recovery of OFX can be attributed to the high sensitivity of this compound to the evaporation step during extraction. Table 2 shows the limits of detection (LOD) and limit of quantification (LOQ) for the whole method. The LOQ ranged from 0.06 to $0.3 \mathrm{ng} \mathrm{g}^{-1}$ wet weight (ww) for $E$. sativa leaves and from 0.3 to $1.25 \mathrm{ng} \mathrm{g}^{-1} \mathrm{ww}$ for $Z$. mays kernels. The LOD ranged from 0.03 to $0.06 \mathrm{ng} \mathrm{g}^{-1} \mathrm{ww}$ for $E$. sativa leaves and from 0.05 to $0.09 \mathrm{ng} \mathrm{g}^{-1} \mathrm{ww}$ for $Z$. mays kernels. In lettuce leaves Wu et al. (2012) reported a lower LOD value for CBZ and an higher value for ATN (compared to our data). The LOD for CBZ in E. sativa is comparable to those reported by Shenker et al. (2011) in pea tissues or by Winker et al. (2010) in ryegrass leaves. Overall, these results demonstrate the consistency of our extraction and clean-up method.

\subsection{Analysis of PAC uptake}

None of the selected pharmaceuticals were detected in the control samples. Conversely, all target PACs were detected in

Table 2

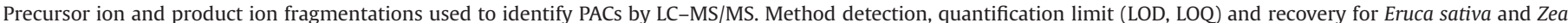
mays matrix.

\begin{tabular}{|c|c|c|c|c|c|c|c|c|}
\hline \multirow[t]{2}{*}{ Compound } & \multirow{2}{*}{$\begin{array}{l}\text { Precursor ion } \\
\mathbf{m z}^{-1}\end{array}$} & \multirow[t]{2}{*}{ Product ion } & \multicolumn{3}{|c|}{ Eruca sativa leaves } & \multicolumn{3}{|c|}{ Zea mays kernels } \\
\hline & & & \multicolumn{3}{|c|}{ ng $g^{-1}$ ww } & \multicolumn{3}{|c|}{$n g g^{-1} w w$} \\
\hline Salbutamol & 240.1 & $166.1,148.1$ & 0.06 & 0.6 & $104 \pm 2.7$ & 0.09 & 0.9 & $95 \pm 2.7$ \\
\hline Atenolol & 267.1 & $190.1,225.2$ & 0.06 & 0.3 & $104 \pm 5.1$ & 0.06 & 0.5 & $102 \pm 5.1$ \\
\hline Ranitidine & 315.2 & $176.1,130.1$ & 0.06 & 0.3 & $48 \pm 3.5$ & 0.09 & 1.25 & $44 \pm 3.5$ \\
\hline Lincomycin & 407.2 & $359.1,126.1$ & 0.03 & 0.06 & $77 \pm 4.6$ & 0.06 & 0.3 & $85 \pm 4.6$ \\
\hline Ofloxacin & 362.2 & $318.1,261.1$ & 0.03 & 0.06 & $37 \pm 3.0$ & 0.06 & 0.6 & $33 \pm 3.0$ \\
\hline Cyclophosphamide & 261.1 & $233.1,140.1$ & 0.06 & 0.3 & $106 \pm 4.3$ & 0.09 & 0.9 & $101 \pm 4.3$ \\
\hline Carbamazepine & 237.1 & $194.2,192.1$ & 0.03 & 0.3 & $84 \pm 2.2$ & 0.05 & 0.5 & $80 \pm 2.2$ \\
\hline Bezafibrate & 362.3 & $274.1,316.1$ & 0.03 & 0.06 & $96 \pm 2.9$ & 0.06 & 0.6 & $75 \pm 2.9$ \\
\hline
\end{tabular}

SD, standard deviation, $n=3$; ww, wet weight. 
E. sativa plants treated with $100 \times$ PAC solution (Table 3 ). For five pharmaceuticals (ATN, LIN, OFX, CBZ, and BZF), the concentrations were above the LOQ and except for BZF, the values were higher than $1 \mathrm{ng} \mathrm{g}^{-1}$ ww. In rocket plants treated with $10 \times$ PAC solution, only LIN and OFX were quantifiable, while SAL and BZF were below the detection limits. ATN, LIN, OFX, CPA, and CBZ were present even in rocket plants irrigated with the $1 \times$ mixture of PACs, while only the levels of LIN and OFX were above the LOQ (Table 3). The Bio-Concentration Factors (BCFs) of PACs in rocket leaves were calculated as the ratio of the drug concentration in plant tissue to the nominal concentration in irrigation water (Table 3). In all cases, the BCFs were $<1$.

We detected the presence of ATN, LIN, and CBZ in the kernels of maize plants irrigated with $100 \times$ PAC mixture, although the levels of these drugs were below the LOQ. These results demonstrate the ability of E. sativa and Z. mays to uptake and translocate some selected PACs from soil irrigated with contaminated water.

The uptake of chemicals (such as drugs) and their translocation through plant organs are conditioned by the hydrophobic nature $(\log P)$ and ionization state of the molecules (and are dependent on the $\mathrm{pKa}$ and $\mathrm{pH}$ of the soil). By using the equation reported by $\mathrm{Wu}$ et al. (2013) we calculated the fraction of neutral molecules $\left(f_{n}\right)$ of the tested PACs in our system. Some of the tested PACs exist predominantly as ionic form and we calculated the $\mathrm{pH}$-dependent octanol-water partition coefficient $\left(\log D_{\text {ow }}\right)$ by using the equations reported in literature (Tanoue et al., 2012; Wu et al., 2013) (Table 1).

CBZ and CPA were in the neutral form in our experimental system (Table 1). CPA uptake was below LOQ probably because of its $\operatorname{low} \log P(0.1)$. At the contrary, the $\log P(2.25)$ of $C B Z$ was optimal for the transport in the shoot (Tanoue et al., 2012). This may explain why the BCF of $\mathrm{CBZ}$ is the highest among the quantified PACs. However, in the present study, the total uptake of CBZ was lower than previously reported values (Tanoue et al., 2012; Herklotz et al., 2010; Shenker et al., 2011; Wu et al., 2010, 2012, 2013; Winker et al., 2010). This discrepancy may primarily be attributed to differences in experimental conditions and in particular to the use of a peat-based horticultural mixture, which may have affected the bioavailability of CBZ (Shenker et al., 2011).

BZF was present primarily in the anionic form, which is hardly absorbed by the root; however its $\log D_{\text {ow }}(0.91)$ may explain the moderate uptake of this chemical. The compounds SAL, ATN, LIN and OFX exist predominantly as cationic forms in our system and their $\log D_{\text {ow }}$ result very low. The slight uptake of these compounds may be attributed to an electric attraction of the cations to the negative charge on the plasmalemma (Tanoue et al., 2012).

When the $\log$ BCFs values were plotted against the $\log D_{\text {ow }}$ values, the coefficient of determination $R^{2}$ was $0.73(p<0.05)$ (Fig. 1). This result suggests that, although the hydrophobicity strongly affects the bioaccumulation of the tested PACs, other processes must be involved to explain completely the BCF values measured.

\subsection{Implications for human health}

The accumulation of some PACs in plants suggests the possibility of dietary uptake, which would potentially pose a risk to human health. We therefore estimated the individual's annual exposure to these PACs based on the highest concentrations of PACs detected in plants and the average daily consumption of leafy vegetables (Dodgen et al., 2013). The annual exposure ranged from $0.035 \mathrm{mg}$ for CBZ to $0.0083 \mathrm{mg}$ for BZF (Table 4). A rough conversion of the expected annual exposure in medical dose equivalents indicated that the direct human risks for these PACs are negligible.

\subsection{Effects of PAC on in vitro germination and plant growth}

We tested the effects of $1 \times, 10 \times$, and $100 \times$ PAC mixtures on germination and root elongation growth in E. sativa and Z. mays. These rapid tests have previously been used to assess the phytotoxicity of PACs on different plant species (Hillis et al., 2011). We found that germination of the control samples was greater than 80 percent, and PAC treatments did not have any significant effect on the percentage of germination (Table 5). However, significant decreases in root length were observed in $Z$. mays seedlings exposed to $10 \times$ and $100 \times$ PAC mixtures (Table 5). These data indicate that the early phases of seed germination are an

$$
\begin{gathered}
y=0.1974 x-0.9096 \\
R^{2}=0.7275
\end{gathered}
$$

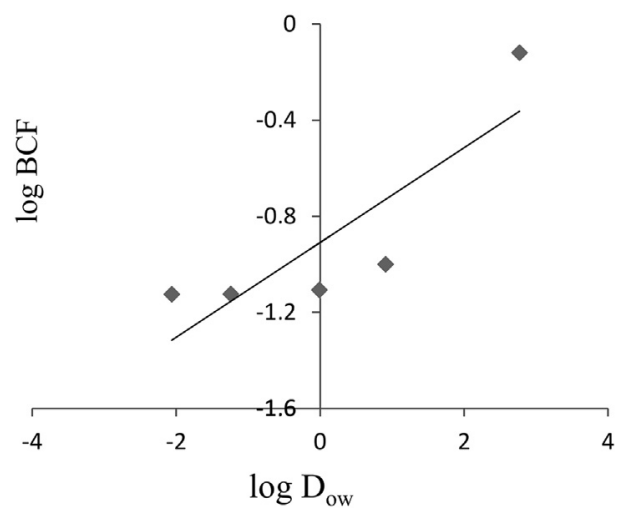

Fig. 1. Correlation between $\log B C F$ and $\log D_{\text {ow }}$ for quantified PACs in $100 \times$ treated Eruca sativa plants.

Table 3

\begin{tabular}{|c|c|c|c|c|c|c|c|}
\hline & \multicolumn{2}{|l|}{$1 \times$} & \multicolumn{2}{|l|}{$10 \times$} & \multicolumn{3}{|l|}{$100 \times$} \\
\hline & Eruca sativa & Zea mays & Eruca sativa & Zea mays & Eruca sativa & $\mathrm{BCF}\left(\operatorname{kg} 1^{-1}\right)$ & Zea mays \\
\hline Salbutamol & $<$ LOD & $<$ LOD & $<$ LOD & $<$ LOD & $<$ LOQ & - & $<$ LOD \\
\hline Atenolol & $<$ LOQ & $<$ LOD & $<$ LOQ & $<$ LOD & $1.80(0.2)$ & 0.075 & $<$ LOQ \\
\hline Ranitidine & $<$ LOD & $<$ LOD & $<$ LOQ & $<$ LOD & $<$ LOQ & - & $<$ LOD \\
\hline Lincomycin & $0.12(0.01)$ & $<$ LOD & $0.28(0.02)$ & $<$ LOD & $1.92(0.3)$ & 0.078 & $<$ LOQ \\
\hline Ofloxacin & $0.10(0.01)$ & $<$ LOD & $0.59(0.07)$ & $<$ LOD & $1.17(0.5)$ & 0.078 & $<\mathrm{LOD}$ \\
\hline Cyclophosphamide & $<$ LOQ & $<$ LOD & $<$ LOQ & $<$ LOD & $<$ LOQ & - & $<$ LOD \\
\hline Carbamazepine & $<$ LOQ & $<$ LOD & $<$ LOQ & $<$ LOD & $2.51(0.4)$ & 0.76 & $<$ LOQ \\
\hline Bezafibrate & $<$ LOD & $<$ LOD & $<$ LOD & $<$ LOD & $0.58(0.1)$ & 0.10 & $<$ LOD \\
\hline
\end{tabular}

Pharmaceuticals uptake, $\mathrm{ng} \mathrm{g}^{-1} \mathrm{ww}$, by Eruca sativa leaves and Zea mays kernels (mean $\pm \mathrm{SD}$ ).

(SD), standard deviation, $n=3$, ww, wet weight. BCF, bioconcentration factor. 
Table 4

Annual human exposure to PACs based on concentration in Eruca sativa calculated in this study and the mean intake of leafy vegetables for a $70 \mathrm{~kg}$ individual.

\begin{tabular}{|c|c|c|c|c|}
\hline & $\begin{array}{l}\text { Tissue } \\
\text { concentration }^{\mathrm{a}} \\
\left(\mathbf{m g ~ k g} \mathbf{~}^{-1} \mathbf{w w}\right)\end{array}$ & $\begin{array}{l}\text { Annual } \\
\text { human } \\
\text { exposure }^{b} \\
(\mathrm{mg})\end{array}$ & $\begin{array}{l}\text { Adult } \\
\text { medical } \\
\text { daily dose } \\
(\mathbf{m g})\end{array}$ & $\begin{array}{l}\text { Medical } \\
\text { dose } \\
\text { equivalent } \\
\text { (\%) }\end{array}$ \\
\hline Atenolol & $0.18 \times 10^{-2}$ & $0.25 \times 10^{-1}$ & 25 & 0.0995 \\
\hline Lincomycin & $0.19 \times 10^{-2}$ & $0.26 \times 10^{-1}$ & 500 & 0.0053 \\
\hline Ofloxacin & $0.12 \times 10^{-2}$ & $0.16 \times 10^{-1}$ & 200 & 0.0081 \\
\hline Carbamazepine & $0.25 \times 10^{-2}$ & $0.35 \times 10^{-1}$ & 200 & 0.0173 \\
\hline Bezafibrate & $0.58 \times 10^{-3}$ & $0.79 \times 10^{-2}$ & 200 & 0.004 \\
\hline
\end{tabular}

a Tissue concentration (ww $=$ wet weight) based on $100 \times$ PACs treatments.

${ }^{\mathrm{b}}$ Annual uman exposure based on leafy vegetable intake of $0.54 \mathrm{~g}$ ww kg body weight ${ }^{-1}$ day $^{-1}$ (U.S. Environmental Protection Agency 2011).

${ }^{\mathrm{c}}$ Human uptake converted in medical dose equivalent.

Table 5

Effects of the PAC mixture on in vitro germination.

\begin{tabular}{llllll}
\hline \multirow{2}{*}{ PAC mixture } & \multicolumn{2}{l}{ Germination $(\%)$} & & \multicolumn{2}{l}{ Root length $(\mathbf{m m})$} \\
\cline { 2 - 3 } \cline { 5 - 6 } & Eruca sativa & Zea mays & & Eruca sativa & Zea mays \\
\hline $\mathbf{0}$ & $92 \pm 9$ & $92 \pm 8$ & & $10 \pm 3$ & $26 \pm 4$ \\
$\mathbf{1} \times$ & $94 \pm 6$ & $82 \pm 8$ & & $8 \pm 3$ & $22 \pm 3$ \\
$\mathbf{1 0} \times$ & $86 \pm 12$ & $76 \pm 11$ & & $8 \pm 4$ & $\mathbf{1 9} \pm \mathbf{4}^{*}$ \\
$\mathbf{1 0 0} \times$ & $84 \pm 6$ & $78 \pm 11$ & & $7 \pm 3$ & $\mathbf{1 7} \pm \mathbf{4}^{*}$ \\
\hline
\end{tabular}

* ANOVA test $(p<0.05)$.

important and vulnerable stage in the $Z$. mays life cycle. The observed decrease in root length to the $10 \times$ and $100 \times$ PAC solutions is likely very relevant to use of reclaimed wastewater for irrigation and potentially for the use of sewage sludge amendment.

No significant differences in the growth or phenotypes of E. sativa or Z. mays plants grown in soil irrigated with PACsspiked vs. non-spiked water were observed (data not shown). Overall, these data confirm the notion that the impact of PACs on higher plants appears to depend on the concentration of the drugs, the plant species, and the experimental conditions (such as the duration and method of exposure). For example, CBZ and ibuprofen do not have toxic effects on ryegrass (Winker et al., 2010), and CBZ, diphenhydramine, and triclocarban do not have toxic effects on various crops (Wu et al., 2012). However, other studies have indicated that the uptake of drugs can inhibit plant growth and induce damage to plants (Boxall et al., 2006; Michelini et al., 2012; Dolliver et al., 2007; Shenker et al., 2011; D’Abrosca et al., 2008, Aristilde et al., 2010; Eggen et al., 2011).

Further research is needed to assess the risk of PACs in areas that employ intensive irrigation and their risk to perennial plants. Moreover, the potential eco-toxicological effects of PAC uptake on soil microbiota and phytophagous insects should also be evaluated.

\section{Acknowledgments}

We would like to thank Silvia Sironi and Ilaria Bruni for their technical support during laboratory analyses.

\section{References}

APAT (2002) Guida tecnica sui metodi di analisi per il suolo e i siti contaminati. Utilizzo di indicatori biologici. APAT, RTI CTN_SSC 2/2002. 〈http://ctntes.arpa. piemonte.it/html/PUBBLICAZIONI.htm〉.

Arnold, K.E., Boxall, A.B., Brown, A.R., Cuthbert, R.J., Gaw, S., Hutchinson, T.H., Jobling, S., Madden, J.C., Metcalfe, C.D., Naidoo, V., Shore, R.F., Smits, J.E., Taggart,
M.A., Thompson, H.M., 2013. Assessing the exposure risk and impacts of pharmaceuticals in the environment on individuals and ecosystems. Biol. Lett. 9, 20130492.

Aristilde, L., Melis, A., Sposito, G., 2010. Inhibition of photosynthesis by a fluoroquinolone antibiotic. Environ. Sci. Technol. 44, 1444-1450.

Brain, R.A., Solomon, K.R., Brooks, B.W., 2009. Targets effects and risks in aquatic plants exposed to veterinary antibiotics. In: Henderson, K.L., Coats, J.R. (Eds.) Veterinary Pharmaceuticals in the Environment. American Chemical Society, Washington DC, pp. 169-189.

Boxall, ABA, Fogg, L, Blackwell, P, Kay, P, Pemberton, E., 2002. Review of Veterinary Medicines in the Environment. Environment Agency, Bristol, UK (Environment Agency R\&D Technical Report P6-012/8TR).

Boxall, A.B., Rudd, M.A., Brook, B.W., Caldwell, D.J., Choi, K., Hickmann, S., Innes, E. Ostapyk, K., Staveley, J.P., Verslycke, T., Ankley, G.T., Beazley, K.F., Belanger, S.E., Berninger, J.P., Carriquiriborde, P., Coors, A., Deleo, P.C., Dyer, S.D., Ericson, J.F. Gagné, F., Giesy, J.P., Gouin, T., Hallstrom, L., Karlsson, M.V., Larsson, D.G., Lazorchak, J.M., Mastrocco, F., McLaughlin, A., McMaster, M.E., Meyerhoff, R.D., Moore, R., Parrott, J.L., Snape, J.R., Murray-Smith, R., Servos, M.R., Sibley, P.K. Straub, J.O., Szabo, N.D., Topp, E., Tetreault, G.R., Trudeau, V.L., Van Der Kraak, G., 2012. Pharmaceuticals and personal care products in the environment: what are the big questions? Environ. Health Perspect. 120, 1221-1229.

Boxall, A.B., Johnson, P., Smith, E.J., Sinclair, C.J., Stutt, E., Levy, L.S., 2006. Uptake of veterinary medicines from soils into plants. J. Agric. Food Chem. 54, 2288-2297.

Calderon-Preciado, D., Matamoros, V., Save, R., Munoz, P., Biel, C., Bayona, J.M., 2013. Uptake of microcontaminants by crops irrigated with reclaimed water and groundwater under real field greenhouse conditions. Environ.Sci. Pollut. Res. 20, 3629-3638.

Carlsson, G., Orn, S., Larsson, J.D., 2009. Effluent from bulk drug production is toxic to aquatic vertebrates. Environ. Toxicol. Chem. 28, 2656-2662.

Castiglioni, S., Bagnati, R. Calamari, D., Fanelli, R., Zuccato, E., 2005. A multiresidue analytical method using solid-phase extraction and high-pressure liquid chromatography tandem mass spectrometry to measure pharmaceuticals of different therapeutic classes in urban wastewaters. J. Chromatogr. A 1092, 206-215.

Corcoran, J., Winter, M.J., Tyler, C.R., 2010. Pharmaceuticals in the aquatic environment: a critical review of the evidence for health effects in fish. Crit. Rev. Toxicol. 40, 287-304.

D’Abrosca, B., Fiorentino, A., Izzo, A., Cefarelli, G., Pascarella, M.T., Uzzo, P., Monaco, P., 2008. Phytotoxicity evaluation of fivepharmaceutical pollutants detected in surface water on germination and growth of cultivated and spontaneous plants. J. Environ. Sci. Health 43, 285-294.

De Lorenzo, M.E., Fleming, J., 2012. Individual and mixture effects of selected pharmaceuticals and personal care products on the marine phytoplankton species Dunaliella tertiolecta. Arch. Environ. Contam. Toxicol. 54, 203-210.

Dodgen, L.K., Li, J., Parker, S., Gan, J.J., 2013. Uptake and accumulation of four PPCP/ EDCs in two leafy vegetables. Environ. Pollut. 182, 150-156.

Dolliver, H., Kumar, K., Gupta, S., 2007. Sulfamethazine uptake by plants from manure-amended soil. J. Environ. Qual. 36, 1224-1230.

Eggen, T., Asp, T.N., Grave, K., Hormazabal, V., 2011. Uptake and translocation of metformin, ciprofloxacin and narasin in forage- and crop plants. Chemosphere $85,26-33$.

Gunnarsson, L., Jauhiainen, A., Kristiansson, E., Nerman, O., Joakim Larsson, D.G., 2008. Evolutionary conservation of human drug targets in organisms used for environmental risk assessments. Environ. Sci. Technol. 42, 5807-5813.

Herklotz, P.A., Gurung, P., Heuvel, B.V., Kinney, C.A., 2010. Uptake of human pharmaceuticals by plants grown under hydroponic conditions. Chemosphere $78,1416-1421$.

Hillis, D.G., Fletcher, J., Solomon, K.R., Sibley, P.K., 2011. Effects of ten antibiotics on seed germination and root elongation in three plant species. Arch. Environ. Contam. Toxicol. 60, 220-232.

Kumar, A., Xagoraraki, I., 2010. Human health risk assessment of pharmaceuticals in water: an uncertainty analysis for meprobamate, carbamazepine, and phenytoin. Regul. Toxicol. Pharmacol. 57, 146-156.

Kümmerer, K., 2008. In: Kümmerer, K. (Ed.), Pharmaceuticals in the Environment: Sources, Fate, Effects and Risks. Springer-Verlag, Berlin Heidelberg.

Mahoney, B.P., Raghunand, N., Bagget, B., Gillies, R.J., 2003. Tumor acidity, ion trapping and chemotherapeutics I. Acid $\mathrm{pH}$ affects the distribution of chemotherapeutic agents in vitro. Biochem. Pharmacol. 66, 1207-1218.

Michelini, L., Reichel, R., Werne, W., Ghisi, R., Thiele-Bruhn, S., 2012. Sulfadiazine uptake and effects on Salix fragilis L. and Zea mays L. plants. Water Air Soil Pollut. 223, 5243-5257.

Munoz, I., Tomas, N., Mas, J., Garcia-Reyes, J.F., Molina-Diaz, A., Fernandez-Alba, A. R., 2010. Potential chemical and microbiological risks on human health from urban wastewater reuse in agriculture. Case study of wastewater effluents in Spain. J. Environ. Sci. Health., Part B 45, 300-309.

OECD, 1984. Terrestrial Plants: Growth test. OECD Guidelines for Testing of Chemicals, Section 2, Paris, Test No. 208. 〈www.oecd.org/env/ehs/testing/ section2-replacedandcancelledtestguidelines.htm $\rangle$.

Piel, S., Baures, E., Thomas, O., 2012. Contribution to surface water contamination understanding by pesticides and pharmaceuticals, at a Watershed Scale. Int. J. Environ. Res. Public Health 9, 4433-4451.

Pomati, F., Castiglioni, S., Zuccato, E., Fanelli, R., Vigetti, D., Rossetti, C., Calamari, D. 2006. Effects of a complex mixture of therapeutic drugs at environmental levels on human embryonic cells. Environ. Sci. Technol. 40, 2442-2447.

Rand-Weaver, M., Margiotta-Casaluci, L., Patel, A., Panter, G.H., Owen, S.F., Sumpter J.P., 2013. The read-across hypothesis and environmental risk assessment of pharmaceuticals. Environ. Sci. Technol. 47, 11384-11395. 
Rang, H.P., Dale, M.M., Ritter, J.M., 1999. Pharmacology. Churchill Livingstone, Edinburgh.

Rivera-Utrilla, J., Sanchez-Polo, M., Ferro-Garcia, M.A., Prados-Joya, G., OcampoPerez, R., 2013. Pharmaceuticals as emerging contaminants and their removal from water. A review. Chemosphere 93, 1268-1287.

Sarmah, A.K., Northcott, G.L., Leusch, F.D.L., Tremblay, L.A., 2006. A survey of endocrine disrupting chemicals (EDCs) in municipal sewage and animal waste effluents in the Waikato region of New Zealand. Sci. Total Environ. 335 98-105.

Sharma, P., Kumar, M., Mathur, N., Singh, A., Bhatnagar, P., Sogani, M., 2013. Health care industries: potential generators of genotoxic waste. Environ. Sci. Pollut. Res. 20, 5160-5167.

Shenker, M., Harush, D., Ben-Ari, J., Chefetz, B., 2011. Uptake of carbamazepine by cucumber plants-a case study related to irrigation with reclaimed wastewater. Chemosphere 82, 905-910.

Tanoue, R., Sato, Y., Motoyamam, M, Nakagawam, S, Shinohara, R., Nomiyama, K. 2012. Plant uptake of pharmaceutical chemicals detected in recycled organic manure and reclaimed wastewater. J. Agric. Food Chem. 60, 10203-11021.

Ternes, T.A., Bonerz, M., Herrmann, N., Löffler, D., Keller, E., Lacida, B.B., Alderm, A. C., 2005. Determination of pharmaceuticals, iodinated contrast media and musk fragrances in sludge by LC/tandem MS and GC/MS. J. Chromatogr. 1067, $213-223$.
USEPA, 1996. Ecological Effects Test Guidelines. OPPTS 850.4200. Seed Germination/Root Elongation Toxicity Test. EPA 712-C-96-154. April 1996. 〈http://www. epa.gov/nscep/index.html $>$.

U.S. Environmental Protection Agency, 2011. Exposure Factors Handbook. National Center for Environmental Assessment, Washington, D.C.

Vannini, C., Domingo, G., Marsoni, M., De Mattia, F., Labra, M., Castiglioni, S., Bracale, M., 2011. Effects of a complex mixture of therapeutic drugs on unicellular algae Pseudokirchneriella subcapitata. Aquat. Toxicol. 101, 459-465.

Winker, M., Clemens, J., Reich, M., Gulyas, H., Otterpohl, R., 2010. Ryegrass uptake of carbamazepine and ibuprofen applied by urine fertilization. Sci. Total. Environ. 408, 1902-1908.

Wu, C., Spongberg, A., Witter, J.D., Sridhar, B.B., 2012. Transfer of wastewater associated pharmaceuticals and personal care products to crop plants from biosolids treated soil. Ecotoxicol. Environ. Saf. 85, 104-109.

Wu, C., Spongberg, A.L., Witter, J.D., Fang, M., Czajkowski, K.P., 2010. Uptake of pharmaceutical and personal care products by soybean plants from soils applied with biosolids and irrigated with contaminated water. Environ. Sci. Technol. 44, 6157-6161.

Wu, X., Ernst, F., Conkle, J.L., Gan, J., 2013. Comparative uptake and translocation of pharmaceutical and personal care products (PPCPs) by common vegetables. Environ. Int. 60, 15-22. 